\title{
Citric acid cough threshold and airway responsiveness in asthmatic patients and smokers with chronic airflow obstruction
}

\author{
B Auffarth, J G R de Monchy, Th W van der Mark, D S Postma, G H Koëter
}

\begin{abstract}
The relation between citric acid cough threshold and airway hyperresponsiveness was investigated in 11 non-smoking patients with allergic asthma (mean $\mathrm{FEV}_{1}$ 94\% predicted) and 25 non-atopic smokers with chronic airflow obstruction (mean FEV $165 \%$ predicted). Cough threshold was determined on two occasions by administering doubling concentrations of citric acid. Seven of the 11 asthmatic subjects and 14 of 25 smokers with chronic airflow obstruction had a positive cough threshold on both test days. Cough threshold measurements were reproducible in both groups (standard deviation of duplicate measurements $1 \cdot 2$ doubling concentrations in asthma, 1.1 doubling concentrations in chronic airflow obstruction). Citric acid provocation did not cause bronchial obstruction in most patients, though four patients had a fall in $\mathrm{FEV}_{1}$ of more than $20 \%$ for a short time on one occasion only. No significant difference in cough threshold was found between the two patient groups despite differences in baseline $F E V_{1}$ values. There was no significant correlation between cough threshold and the provocative concentration of histamine causing a $20 \%$ fall in $\mathrm{FEV}_{1}\left(\mathbf{P C}_{20}\right)$ histamine in either group. Thus sensory nerves can be activated with a tussive agent in patients with asthma and chronic airflow obstruction without causing bronchial smooth muscle contraction.
\end{abstract}

Cough and shortness of breath are common features both in atopic patients with asthma and in smokers with chronic airflow obstruction. Airway responsiveness to inhaled stimuli such as histamine or methacholine is increased in both groups of patients. The observation that these stimuli can induce both shortness of breath and cough suggests that bronchoconstriction and the cough reflex are interrelated and that cough may improve with treatment with bronchodilators. ${ }^{1}$ Provocation tests with different agents and treatment with drugs that influence different pathways, however, suggest that cough and bronchial obstruction are separate conditions. ${ }^{2-5}$ For example, atropine blocks the bronchoconstriction induced by inhaled distilled water but not cough, whereas lignocaine inhibits cough only. ${ }^{2}$ A reproducible cough measurement that does not cause appreciable bronchoconstriction may be useful for separating bronchoconstriction and cough in diagnosis and treatment. The aim of the present study was to assess the reproducibility of cough threshold measurements with citric acid inhalation in asthmatic patients who did not complain of cough and in current smokers with chronic airflow obstruction who had cough, and to find out whether citric acid challenge could discriminate between the two groups. The cough response was compared with airway responsiveness to histamine.

\section{Methods \\ PATIENTS \\ Two groups of patients were investigated. \\ Group 1: Non-smoking subjects with atopic asthma}

This group consisted of six men and five women, aged 19-33 (mean 26) years. All patients reported episodes of dyspnoea and wheezing and had positive skin test responses to at least two common allergens, including house dust mite. All showed an increased airway responsiveness to inhaled histamine, defined as a provocative concentration of histamine that caused a $20 \%$ fall in $\mathrm{FEV}_{1}\left(\mathrm{PC}_{20}\right.$ histamine) below $16 \mathrm{mg} / \mathrm{ml}$ (see below). Their forced expiratory volume in one second $\left(\mathrm{FEV}_{1}\right)$ was over $70 \%$ of the predicted value (mean $\mathrm{FEV}_{1} \%$ pred $\left.94 \%\right) .{ }^{6}$ None had had a cough during the past three months.

\section{Group 2: Smokers with chronic airflow} obstruction

This group consisted of 24 men and one woman who had smoked at least one cigarette a day for at least five years. Their ages ranged from 45 to 70 (mean 58) years. All had negative skin test responses to common allergens and a $\mathrm{PC}_{20}$ histamine value below $16 \mathrm{mg} / \mathrm{ml}$. $\mathrm{FEV}_{1} \%$ pred ranged from $35 \%$ to $85 \%$ (mean $65 \%$ ). The $\mathrm{FEV}_{1}$ after $0.5 \mathrm{mg}$ inhaled terbutaline was below $90 \%$; the difference between $\mathrm{FEV}_{1} \%$ pred before and after $0.5 \mathrm{mg}$ terbutaline ranged from $5 \%$ to $20 \%$. All patients had had a chronic cough for at least five years and produced sputum in various amounts.

All patients were considered to be clinically stable with no respiratory tract infections or use of oral corticosteroids for at least two months before the study. Inhaled medication was with- 
held for at least 12 hours and theophylline for at least 48 hours before the study.

DETERMINATION OF PC $_{20}$ HISTAMINE

Inspiratory slow vital capacity and $F E V_{\text {, were }}$ measured with a water sealed spirometer (Lode, Groningen). A Wiesbadener Doppelinhalator, nebulised particle size $5 \mu \mathrm{m}$ (output $0.12 \mathrm{ml} / \mathrm{min}$ ), was used with an airflow of $8 \mathrm{l} /$ min. ${ }^{7}$ The patients inhaled phosphate buffered saline (PBS) followed by doubling concentrations of histamine (acid) phosphate ranging from 0.03 to $16 \mathrm{mg} / \mathrm{ml}$. Each concentration was inhaled for two minutes during tidal breathing with an interval between the inhalations of five minutes. The $\mathrm{FEV}_{1}$ values were measured 30 seconds and 90 seconds after each inhalation. The inhalations were stopped as soon as $\mathrm{FEV}_{1}$ had fallen by $20 \%$ or more from the baseline value (determined after phosphate buffered saline).

\section{CITRIC ACID COUGH THRESHOLD}

The cough threshold was defined as the first concentration of citric acid that induced at least one cough during inhalation, provided that the following concentration also led to at least one cough. ${ }^{8}$ When cough occurred with the highest dose, this was considered to be the threshold. When no cough occurred at the highest concentration the cough threshold was arbitrarily set at one dose higher than the maximum dose given, $1024 \mathrm{mg} / \mathrm{ml}$. Citric acid was nebulised in the same way as histamine with a valve in the circuit (see fig 1) to prevent rebreathing. Patients inhaled doubling concentrations of citric acid diluted in saline from 1 to $512 \mathrm{mg} / \mathrm{ml}$ during tidal breathing for one minute. $\mathrm{FEV}_{1}$ measurements were carried out 30 and 90 seconds after inhalation. The interval between doses was at least five minutes. Patients were informed that some irritation of the throat could occur during inhalation, but did not know that cough was being measured. Coughs were recorded by a pressure measurement at

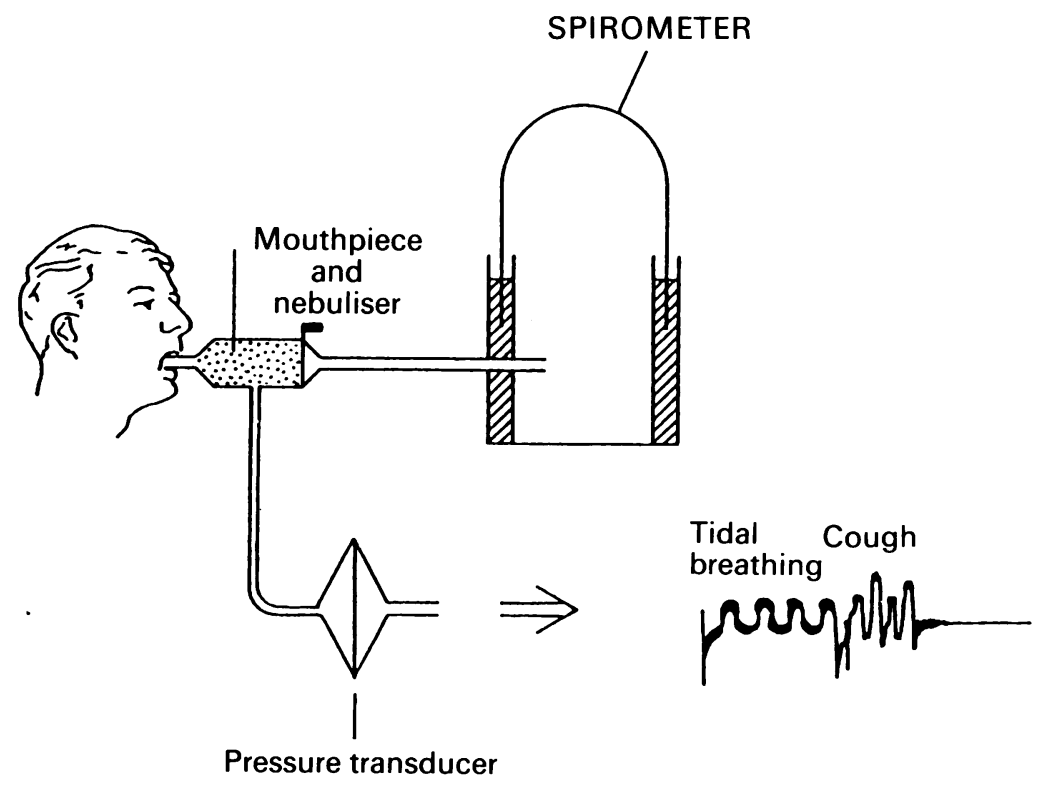

Figure 1 Method of recording of cough by pressure measurements. $\Gamma=$ valve. the mouthpiece of the spirometer and a cough was defined as a change in the tidal breathing pressure pattern-that is, as a short sudden increase of the peak pressure (fig 1). Normal values in our laboratory are $512 \mathrm{mg} / \mathrm{ml}$ and above. The geometric mean threshold value for eight healthy volunteers in our laboratory was $724 \mathrm{mg} / \mathrm{ml}$. All subjects had values of $512 \mathrm{mg} /$ $\mathrm{ml}$ or above.

\section{STUDY DESIGN}

The assessments were carried out at the same time of day on two study days, within two weeks.

On day 1 a histamine challenge was performed. When the $\mathrm{FEV}_{1}$ had returned to a value above $85 \%$ of the highest value on that day a citric acid challenge was carried out to determine the cough threshold.

On day 2 the smokers with chronic airflow obstruction followed the same protocol, but the asthmatic subjects underwent the citric acid challenge only.

The protocol was approved by the hospital medical ethics committee and written informed consent was obtained from each patient.

\section{ANALYSIS}

The citric acid cough thresholds and $\mathrm{PC}_{20}$ histamine values were $\log$ transformed before analysis. Reproducibility was measured as the standard deviation of the difference in duplicate measurements:

$$
(\mathrm{SD})^{2}=\frac{\sum \mathrm{d}^{2}}{2 \mathrm{k}},
$$

$\mathrm{d}$ being the difference between two measurements and $k$ the number of patients.

Groups were compared by means of Student's $t$ test for unpaired observations. The correlation coefficient between the citric acid cough threshold and the $\mathrm{PC}_{20}$ histamine was calculated from the geometric mean value of the two measurements. Mean $\mathrm{FEV}_{1}$ values on the two days were used to compare initial $\mathrm{FEV}_{1}$ with both citric acid cough threshold and $\mathrm{PC}_{20}$ histamine.

\section{Results}

Clinical characteristics of the 11 asthmatic subjects and 25 smokers with chronic airflow obstruction are presented in the table. Not all patients reached the cough threshold on one or both occasions. In the asthmatic subjects a threshold value was obtained in seven, two had no response on either test day, and two had a response on one day only. In the smokers 14 had a response on both days, four on neither day, and seven on one day only.

\section{REPRODUCIBILITY OF COUGH THRESHOLD} MEASUREMENTS

The geometric mean cough threshold in the asthmatic responders on day 1 and day 2 was 105 and $57 \mathrm{mg} / \mathrm{ml}$ respectively. The thresholds in the responders with chronic airflow obstruction on days 1 and 2 were 105 and $100 \mathrm{mg} / \mathrm{ml}$ (fig 2). 
Clinical characteristics of the groups of patients (mean $(S D)$ values unless otherwise specified)

\begin{tabular}{|c|c|c|}
\hline & $\begin{array}{l}\text { Chronic } \\
\text { airflow } \\
\text { obstruction }\end{array}$ & Asthma \\
\hline No of patients & 25 & 11 \\
\hline Age $(y)$ & $57 \cdot 6(3.4)$ & $25 \cdot 6(4 \cdot 9)$ \\
\hline No of males & 24 & 6 \\
\hline Smokers (\%) & 100 & 0 \\
\hline $\mathrm{FEV}_{1}(1)$ & $1.94(0.49)$ & $3.76(0.90)$ \\
\hline \multicolumn{3}{|l|}{$\mathrm{FEV}_{1}$ (\% pred) } \\
\hline Day 1 & $65 \cdot 0(13 \cdot 4)$ & $93 \cdot 8(11 \cdot 6)$ \\
\hline Day 2 & $64.4(13.8)$ & $93.0(11.9)$ \\
\hline \multicolumn{3}{|c|}{ Geometric mean $\mathrm{PC}_{20}(\mathrm{mg} / \mathrm{ml})$} \\
\hline Day 1 & 0.99 & $2 \cdot 82$ \\
\hline Day 2 & 1.07 & - \\
\hline \multicolumn{3}{|c|}{ Geometric mean cough threshold $(\mathrm{mg} / \mathrm{ml})$} \\
\hline Day 1 & 251 & 214 \\
\hline Day 2 & 209 & 144 \\
\hline
\end{tabular}

$\mathrm{PC}_{20}$-provocative concentration of histamine causing a $20 \%$ fall in FEV

The standard deviation of the difference in cough threshold measurements on the two occasions were $1 \cdot 2$ and $1 \cdot 1$ doubling dose (DD) in the asthmatic patients and the smokers with chronic airflow obstruction respectively.

REPRODUCIBILITY OF PC 20 HISTAMINE

The standard deviation of the difference in duplicate measurements of $\mathrm{PC}_{20}$ histamine in the smokers with chronic airflow obstruction was $0.79 \mathrm{DD}$.

\section{CITRIC ACID THRESHOLD, PC $_{20}$ HISTAMINE AND FEV}

There was no significant difference in geometric mean values of cough threshold and $\mathrm{PC}_{20}$ histamine between the two groups. In the asthmatic patients and the smokers with chronic airflow obstruction the geometric mean values for the citric acid threshold were 78 and $102 \mathrm{mg} / \mathrm{ml}$, and the geometric means of $\mathrm{PC}_{20}$ histamine 2.45 and $1.23 \mathrm{mg} / \mathrm{ml}$.

$\mathrm{FEV}_{1} \%$ pred in the asthmatic subjects $(93 \%)$ was significantly higher than that in the
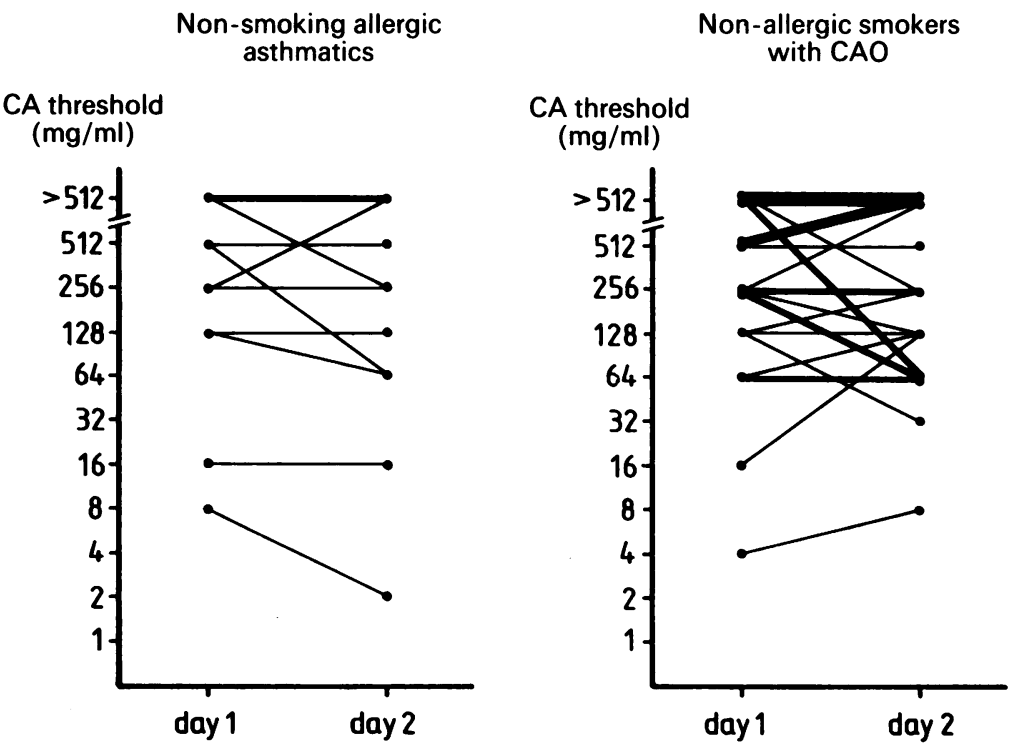

Figure 2 Citric acid (CA) cough threshold histamine values for individual patients with asthma and chronic airflow obstruction (CAO). smokers with chronic airflow obstruction $(65 \%)-p<0.001$.

CITRIC ACID THRESHOLD, PC $_{20}$ HISTAMINE, AND INITIAL FEV

There was no significant correlation between citric acid threshold and $\mathrm{PC}_{20}$ histamine in either group (fig 3). When the first measurements of $\mathrm{PC}_{20}$ histamine and citric acid cough threshold were analysed in the two groups, patients with a positive threshold value $(\mathrm{n}=$ 26) had a $\mathrm{PC}_{20}$ value (geometric mean 1.42 $\mathrm{mg} / \mathrm{ml}$ ) similar to that of the ones who did not reach a threshold $\left(\mathrm{n}=10\right.$; geometric mean $\mathrm{PC}_{20}$ $1.23 \mathrm{mg} / \mathrm{ml}$ ). The same was true for the patients with chronic airflow obstruction: $\mathrm{PC}_{20}$ was 0.78 $\mathrm{mg} / \mathrm{ml}$ in eight non-responders and $1 \cdot 21 \mathrm{mg} / \mathrm{ml}$ in 17 responders.

CITRIC ACID CHALLENGE AND CHANGES IN FEV, $\mathrm{FEV}_{1}$ values in the asthmatic patients after citric acid challenge were within $5 \%$ of the prechallenge values in all subjects. Four of the smokers with chronic airflow obstruction had a fall in $\mathrm{FEV}_{1}$ of more than $20 \%$, however. This was observed on one test day only and FEV returned to baseline within a few minutes. The mean fall in $\mathrm{FEV}_{1}$ in the smoking group with chronic airflow obstruction was $-1 \cdot 3 \%$.

\section{Discussion}

The present study shows that the standard deviation of duplicate measurements of citric acid is just above one dose step, which is slightly less reproducible than $\mathrm{PC}_{20}$ histamine measurements. Inhalation of citric acid did not cause bronchial obstruction in most patients. The fall in FEV in four patients was probably due to fatigue, as it was seen on only one of the two test days and returned to baseline within a few minutes. There was no significant correlation between $\mathrm{PC}_{20}$ histamine and citric acid threshold. In the asthmatic subjects with no history of cough the citric acid cough threshold was similar to the values obtained in the smokers with chronic airflow obstruction and cough. Normal healthy volunteers did not reach a threshold with the citric acid challenge.

Bickerman et al were the first to use citric acid to provoke cough. ${ }^{9}$ Unlike the well defined and widely accepted protocols for assessment of airway hyperresponsiveness using histamine, for example, no uniformly standardised cough provocation test is available. Some investigators use a single breath technique to administer the citric acid aerosol, others prefer continuous inhalation of varying concentrations for a fixed time. ${ }^{238-15}$ With the single breath technique the subject usually attempts to inhale from a known lung volume to total lung capacity during a preset time interval to avoid the effects of a rapid inhalation on airway calibre. This method requires training and good cooperation of the patients. Continuous inhalation is easier to perform but may have the disadvantage that once cough occurs the inhalation pattern is altered. The concentrations of citric acid given by different investigators vary substantially. In some studies the 


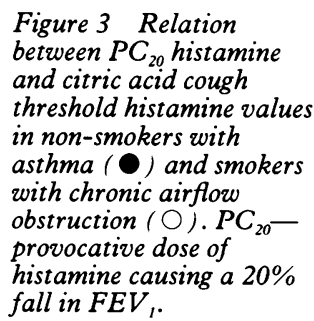

agents are inhaled in random order to avoid a cumulative effect, whereas in other studies increasing concentrations with one to five minute intervals to monitor the response are used. ${ }^{15}$ Cough usually occurs during nebulisation. Cough can be measured in terms of a cough index, which is the number of coughs divided by the time until cough occurs, a doseresponse curve based on cough frequency, or the cough threshold. ${ }^{11}$

Our method of citric acid inhalation was analogous to the well defined protocol for histamine inhalation. The time until cough occurred was recorded, but did not diminish consistently with increasing concentrations. As cough was considered as an "on-off" phenomenon the lowest concentration that induced cough, the "cough threshold," was chosen as a measure of cough. Patients could easily follow the instructions and the method proved to be reproducible.

Cough and bronchoconstriction are frequently provoked by the same substances. Pronounced bronchoconstriction may cause cough by mechanical stimulation of cough receptors. To investigate cough separately an agent is required that causes little or no bronchoconstriction. Reports on the bronchoconstrictive effects of citric acid are contradictory. Braman and coworkers found that citric acid induced bronchoconstriction and cough, with no correlation between the two responses. ${ }^{12}$ Simonsson and coworkers observed an increase in airflow resistance reaching a maximum within 30 seconds after inhalation and returning to control values in one to three minutes. ${ }^{13}$ In the present study $\mathrm{FEV}_{1}$ was measured 30 seconds after the inhalation of citric acid and the fall in $\mathrm{FEV}_{1}$ was small in most patients. This is in accordance with the findings in other studies, where neither airway resistance nor $\mathrm{FEV}_{1}$ changed significantly after citric acid inhalation. ${ }^{101617}$

Asthma is characterised by increased airway responsiveness to histamine and, as clinicians are aware, often presents with cough. Airway hyperresponsiveness is not, however, a prerequisite for cough. ${ }^{141819}$ Okayama and coworkers were unable to find a relation between cough threshold and airway hyperresponsiveness in asthmatic subjects or patients with acute bronchitis. ${ }^{14}$ Fuller and Choudry observed a higher cough threshold in patients with non-productive cough than in the normal population. The increase in cough threshold was not, however, associated with asthma. ${ }^{16} \mathrm{~A}$ review on the relation between cough and wheeze in asthma concluded that the two symptoms are closely related but not necessarily dependent on each other. ${ }^{20}$ This observation was confirmed in our study by the lack of correlation between $\mathrm{PC}_{20}$ histamine and citric acid threshold in both groups of patients.

The smokers with chronic airflow obstruction in this study had a lower baseline $\mathrm{FEV}_{1}$ than the asthmatic subjects, but citric acid thresholds were similar. Thus the cough threshold does not seem to be affected by the difference in baseline lung function between the two groups. It may be possible to activate sensory nerves with a tussive agent without contracting the bronchial smooth muscle. As a consequence it may be helpful to diagnose cough and evaluate the treatment of cough separately from bronchoconstriction. Citric acid may be a suitable agent in this respect as it does not cause substantial bronchoconstriction. 
1 Salem H, Aviado DM. Antitussive drugs. Am J Med Sci 1964;247:585-600.

2 Sheppard D, Rizk NW, Boushey HA, Bethel RA. Mechanism of cough and bronchoconstriction induced by distilled water aerosol. Am Rev Respir Dis 1983;127:691-4.

3 Eschenbacher WL, Boushey HA, Sheppard D. Alteration in osmolarity of inhaled aerosols cause bronchoconstriction and cough, but absence of a permanent anion causes cough alone. Am Rev Respir Dis 1984;129:211-5.

4 Belcher N, Rees PJ. Effects of pholcodine and salbutamol on citric acid induced cough in normal subjects. Thorax 1986;41:74-5.

5 Fuller RW, Collier JG. Sodium cromoglycate and atropine block the fall in FEV but not the cough induced by hypotonic mist. Thorax 1984;39:766-70.

6 Quanjer PhD. Standardized lung function testing. Clin Respir Physiol 1983;19:3-28.

7 Ferron GA, Kerrebijn KF, Weber J. Properties of aerosols produced with nebulizers commonly used in medicine. Am Rev Respir Dis 1976;114:899-908.

8 Banner AS, Drummer A. Relationship between citric acid cough threshold and ventilatory response to $\mathrm{CO}_{2}$ in normal subjects [abstract]. Am Rev Respir Dis 1987; 135(suppl):A489.

9 Bickerman HA, Barach AL. The experimental production of cough in human subjects induced by citric acid aerosols. Preliminary studies on the evaluation of antitussive agents. Am J Med Sci 1954;228:156-63.

10 Pounsford JC, Birch MJ, Saunders KB. Effect of bronchodilators on the cough response to inhaled citric acid in normal and asthmatic subjects. Thorax $1985 ; 40: 662-7$.

11 Pounsford JC, Saunders KB. Diurnal variation and adapta- tion of the cough response to citric acid in normal subjects. Thorax 1985;40:657-61.

12 Braman SS, Amico C, Steigman D, Millman RP. Cough and bronchoconstrictive reflexes in normal elderly subjects [abstract]. Am Rev Respir Dis 1987;135(suppl):A476.

13 Simonsson BG, Jacobs FM, Nadel JA. Role of autonomic nervous system and the cough reflex in the increased responsiveness of airways in patients with obstructive airway disease. $J$ Clin Invest 1967;46:1812-8.

14 Okayama $M$, Katsumata U, Biana RT, Nishimura Y, Nishimaki $\mathrm{C}$, Inoue $\mathrm{H}$, et al. Dose related cough response to citric acid and relationship to airway reactivity [abstract]. Am Rev Respir Dis 1987;135(suppl):A321.

15 Morice A, Smolira M, Lowry R, Brown MJ, Higgenbottam $T$. Demonstration of rapid adaptation of the cough reflex in man [abstract]. Am Rev Respir Dis 1988;137:S269.

16 Fuller RW, Choudry ND. The sensitivity of the cough reflex in patients with cough [abstract]. Am Rev Respir Dis 1988;137:S162

17 Heijrman R, De Backer W, Willemen M, Bogaerts $M$ Vermeire $P$. Effect of nedocromil sodium on citric acid induced cough in asthmatic subjects. Bull Eur induced cough in asthmatic
Physiopathol Respir 1987;23:S12.

18 Amaro Galvez R, McLaughlin FJ, Levinson $\mathrm{H}$. The role of the methacholine challenge in children with chronic cough. J Allergy Clin Immunol 1987;79:331-5.

19 Arnup ME, Fleetham JA. Cough threshold: variation within a normal population and relationship to bronchial reactivity. Am Rev Respir Dis 1981;129(suppl):123.

20 Anonymous. Cough and wheeze in asthma: are they interdependent? Lancet 1988;i:447-8. 